\title{
Do Governors Lead or Follow? Timing of Stay-at-Home Orders
}

\author{
Bryan C. McCannon ${ }^{1}$
}

Published online: 21 September 2021

(c) EEA 2021

\begin{abstract}
I investigate the timing of the Stay-at-Home orders. I use daily Google search data to track early interest in the novel Coronavirus pandemic. I ask whether governors responded to heightened concern (i.e., following) or if their decisions are independent of citizen sentiment (i.e., leading). I show that Stay-at-Home orders were initiated sooner in states that saw early, heightened in the virus. This suggests that governors follow voters' opinions, preferences, and sentiments. Exploring potential heterogeneous effects, there is not a difference in the size of this effect between Republican and Democrat governors, nor is there a difference between those up for re-election in 2020 and those not. I do find that governor responsiveness is related to the state's economic freedom and the governor's approval rating just before the pandemic. In a novel environment without precedence, governors in the USA set policy in accord with voter preferences.
\end{abstract}

Keywords Coronavirus · Google Trends · Governor $\cdot$ Responsiveness · Stay-atHome orders

\section{Introduction}

On December 31, 2019 China reported a cluster of pneumonia cases related to the Wuhan Wholesale Market and confirmed that these cases were due to the novel Coronavirus on January 7, 2020. Since then, the virus has spread around the world. The first case in the USA was on January 19, 2020 (Holshue et al. 2020). It has spread rapidly and led to unprecedented disruptions to daily life and the economy, not to mention the catastrophic loss of life.

In the USA, the virus led to unprecedented policies enacted by state governors. Almost all states implemented Stay-at-Home orders requiring non-essential

\section{Bryan C. McCannon}

bryan.c.mccannon@gmail.com

1 Department of Economics, West Virginia University, 1601 University Avenue,

Morgantown 26506, USA 
businesses to close and asking residents to shelter in place and social distance. The economic destruction of the Stay-at-Home orders cannot yet be fully measured, but can only be balanced by the number of lives saved by slowing the virus's spread and keeping health care facilities from being over-run.

Unfortunately, this novel pandemic provides the opportunity to assess gubernatorial decision making. While state governors received information and suggestions from national and international sources, they were free to act independently. The orders issued did not receive legislative approval or were subject to Federal mandates and restrictions. Some governors acted (relatively) quickly, while other governors delayed, and some never implemented these lockdowns. The goal of this study is to understand this variation in decision making.

It is unclear whether the benefit to these orders outweighed the costs, and we may never know. The variation in decision making, though, provides the opportunity to ask whether governors in the USA are leaders or followers. That is, do they respond to citizen demands, preferences, and opinions in a responsive manner (i.e., following their citizens)? Alternatively, leaders can be expected to respond to a new situation by doing what is right, given the information they have. A leading governor's choices, then, would not necessarily be conditioned on voter's assessments. Followers are more likely to respond to opinion polls and popular opinion, leaders act regardless. The novel Coronavirus provides a novel opportunity to evaluate gubernatorial decision making. It is a never-seen-before event. Each governor is confronted with the same information (but potentially varying magnitudes of benefits and harms to their decision) and is free from Federal government intervention.

The dilemma is how to gauge citizen concern. Public opinion polling is sparse as there was no comprehensive daily/weekly data collection spanning all states. Identifying sentiment by protests or other collective actions are not possible given the shelter in place requirements. The approach I follow here is to track Google searches for "Coronavirus". Google provides daily search behavior separate for each state. The shutdown of businesses, churches, and schools left many at home leaving them the internet (and television) as their only access to the outside world. Google searching is a good proxy measurement for residents' concern over the virus.

I ask whether heightened interest in the virus early in its spread can explain which governors implemented the Stay-at-Home orders first. If states where searches are relatively higher earlier in the pandemic are those states that implement the lockdowns earlier, while late adopting states are those with later responsiveness by the citizens, then I argue this is evidence of governors as followers. If the implementation of the Stay-at-Home orders are unrelated to Google searching, then governors are more likely to be leaders.

The question connects to the fundamental divergence of political competition as being either one of Downs (1957) or Citizen Candidates (Osborne and Slivinski 1996; Besley and Coate 1997). In the former, politicians do not express personal preferences but simply announce and take on the policies preferred by voters. Political competition can be expected to lead to policy representing the median voter (Black 1948) and, therefore, adjusts as the median voter's preferences change. 
Politicians as citizen-candidates, on the other hand, enact policy based on their own preferences and knowledge. The central question there, then, is to what degree does policy diverge from what is preferred by the voters. ${ }^{1}$

I find strong evidence that states with relatively more Google searches for "Coronavirus" in February and early March of 2020 are those states that implemented the Stay-at-Home orders earlier. This effect is not explained only by searches in week prior to the order, but rather are driven by how much concern residents of the state had prior to the dramatic events and closures of mid- and late-March. Further, how quickly a state issued the order is not related to cumulative death toll. Governors are followers.

Exploring heterogeneous effects, I am unable to document differentiable impacts by partisan affiliation. Unlike reporting of distinctions between blue and red states, the relationship between the relative amount of internet searching and gubernatorial policymaking is basically identical for Republican and Democrat governors. In addition, I do not find a difference between those governors who are up for re-election in 2020 and those who are not. I do find, however, that governors of more economically free states are less likely to be responsive to resident concerns. ${ }^{2}$ Finally, I find that the effect is smaller for governors who have higher approval ratings just before the pandemic hit. This suggests that popular governors and those in freer states are more likely to be leaders.

This note contributes to the rapidly growing and presumably large future literature on the economic, legal, psychological, health, and political ramifications of the novel Coronavirus. ${ }^{3}$ Importantly, it informs the literature on democratic accountability and specifically the literature on state governors' decision making (Simon 1989; Lowry et al. 1998).

\section{Data}

A number of data sources were brought together in my analysis. First, Google Trends data was downloaded. I used the keyword "Coronavirus". I accessed the data on April 25, 2020 covering searches from January 1, 2020 to April 23, 2020. Daily figures from each of the 50 states, along with the District of Columbia and the aggregated search history for the USA, was collected. This generates a state-day panel data set of 5763 observations.

Google Trends data comes normalized by the peak observation's value. Since I downloaded data for each state individually, a state's daily search value is normalized by its peak. In the upcoming econometric analysis, I use state fixed

\footnotetext{
1 For conciseness, I do not attempt to document and review the expansive literature on political competition with these two frameworks.

2 This work complements (Hall and McCannon 2021) analysis of the relationship between economic freedom and these orders.

3 The closest such reference is Brodeur et al. (2020) who uses Google Trends data on 12 health-related terms investigating how the implementation of a state's Stay-at-Home order affected their searches.
} 
Fig. 1 Timing of the Stay-atHome Orders. Proportion of states with an order in effect on the $y$-axis. Number of days since January 1, 2020 provided on the $\mathrm{X}$-axis

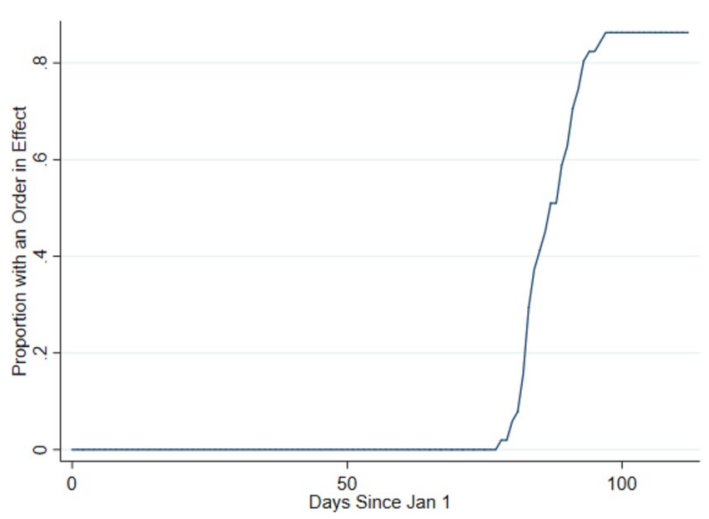

effects, which will account for the peak value since it is time invariant. The value of Coronavirus $_{d s}$ can be viewed as the volume of internet-based attention given to the novel Coronavirus on day $d$ in state $s .{ }^{4}$ It is worth pointing out that the volume of Google searches is not necessarily an indication of support for a lockdown order. Both supporters of the Stay-at-Home orders and those with reservations can be expected to be actively searching for new information online. The variable Coronavirus $_{d s}$ captures the amount of interest.

Second, I collected the date at which each state's Stay-at-Home order took effect. To build this list, I used NBC's tool provided on their website. This was crosschecked with Ballotpedia's Coronavirus information site. For the few discrepancies, I did a Google search to find a third source as a tie-breaker. The few discrepancies that existed were because one source mistakenly recording the date of the announcement, rather than the date of implementation. To be consistent, I record each order by the date at which it went into effect. Usually, announcements came one or two days prior. Therefore, the variable Lockdown $_{d s}$ equals one if state $s$ has a Stay-atHome order in effect on day $d$.

This process identifies those states that have not issued a statewide stay-at-home order. There were seven such states (Arkansas, Iowa, Nebraska, North Dakota, South Dakota, Utah, Wyoming). It is worth pointing out that I am focusing only on statewide orders, which are issued by Governors. Quite a few cities and counties in the USA implemented their own restrictions. These are not included here. For example, while Utah's Governor, Gary Herbert, did not issue an order, four of the counties, including the county that contains Salt Lake City, did so. The first state to have restrictions was California (March 19), followed shortly by Illinois, New Jersey, and New York (March 21). The last states to implement the orders were Alabama (April 4), Missouri (April 5), and South Carolina (April 7). It is this variation in timing that I intend to explain. Figure 1 graphically depicts the timing of the orders.

\footnotetext{
${ }^{4}$ Other, related search keywords were considered. The correlation between daily searches of the word "Coronavirus" and "COVID-19" at the national level is quite high $(\rho=0.87)$. Similarly, its correlation with "SARS" is also extremely high $(\rho=0.76)$. Consequently, I limit my analysis here to term "Coronavirus".
} 
Table 1 Descriptive statistics

\begin{tabular}{llllll}
\hline Day-state data set & Mean & SD & Min. & Med. & Max. \\
\hline Coronavirus (relative \# of daily Google searches) & 26.03 & 27.11 & 0 & 14 & 100 \\
Lockdown (= 1 if state has order in effect that day) & 0.200 & 0.400 & 0 & 0 & 1 \\
Deaths (daily cumulative \# of deaths) & 86.62 & 651.79 & 0 & 0 & 15302 \\
Governors & & & & & \\
Republican & $52.9 \%$ & & & & \\
Running for Re-election in 2020 & $19.6 \%$ & & & \\
Economic Freedom (avg.) & 6.258 & & & & \\
Approval rating (avg.) & $61.2 \%$ & & & & \\
\hline
\end{tabular}

Daily data between January 1 and April 22, 2021 used; $N=5763$

I record the name and political party affiliation of each Governor. This will allow me to evaluate whether partisanship or the presence of an upcoming election matter. In addition, to explore other heterogeneous effects, I obtain information on each state's economic institution. Specifically, I use the Economic Freedom of North America (EFNA) as a measure of each state's economic institutions (Stansel et al. 2019). The Fraser Institute publishes annually an index measuring economic freedom of each state in the USA, along with the Canadian provinces and Mexican states. It consists of measurements in three distinct areas: government expenditures, taxation, and regulation. These components are merged into an index value ranging between 0 and 10 . The most recent economic freedom data is from $2017 . .^{5}$

In addition, I collect public opinion poll data. Morning Consult engages in extensive surveying on political sentiment. Each quarter they publish approval ratings for each governor in the USA. The most recent public opinion polls at the time of the orders were as of December 31, 2019. Since this date corresponds with the first public announcement in China, before it was confirmed to be Coronavirus, the opinion poll data records residents' assessment of their governor prior to the pandemic. ${ }^{6}$ Morning Consult provides a breakdown on the percentage of those surveyed in a state who approve, don't know, and disapprove of the governor. To create a single variable, I define Approve s $_{\mathrm{s}}=\frac{\% \text { approve }}{\% \text { approve }+\% \text { disapprove }}$ as the governor's approval value. The search data is normalized so that each state's peak value is equal to 100 . The 'typical' day during this time period has one-quarter of this level of internet searching. It is the timing of this search behavior that will be explored in the next section. Table 1 provides simple descriptive statistics.

Republicans held a slight edge in the number of seats occupied in 2020. Approval of state governors was high. The standard deviation is 0.119 , which suggests that there is quite a bit of variation in voter's opinions about their leadership.

\footnotetext{
${ }^{5}$ Data and a description of the methods can be found here: https://www.fraserinstitute.org/sites/default/ files/economic-freedom-of-north-america-2019-US-edition.pdf.

${ }^{6}$ Data and a description of the methods can be found here: https://morningconsult.com/governor-ranki ngs/.
} 
Fig. 2 Google Searches for "Coronavirus". Daily number of searches, relative to the peak on March 12, 2020, for the search term "Coronavirus" in the USA between January 1, 2020 and April 23, 2020

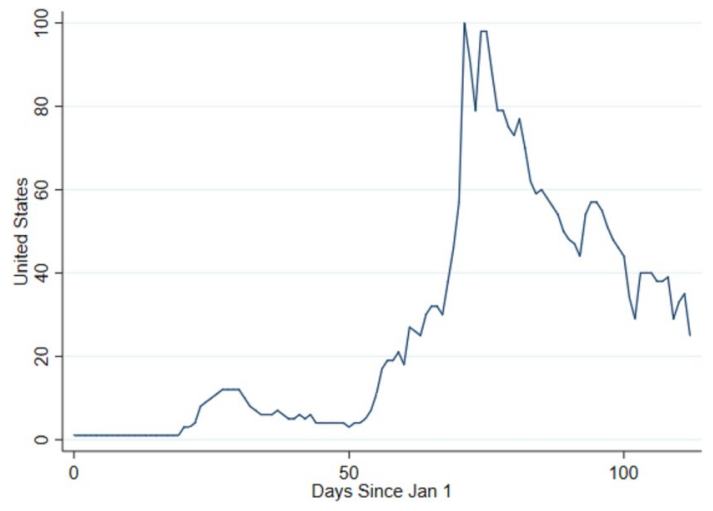

The governors of Massachusetts $(87.3 \%)$ and Wyoming $(86.3 \%)$ have the highest approval ratings, while the governors of Kentucky (38.3\%) and Hawaii (35.6\%) have the lowest. With a standard deviation of 0.8 , economic freedom has little variation amongst the states. New Hampshire (7.93) and Florida (7.90) are the most economically free states, while New York (4.49) and West Virginia (4.77) are the least free.

\section{Results}

\section{Suggestive Findings}

First, the explanatory variable is amount of Google searching for the term "Coronavirus" in the country. Figure 2 depicts the amount of searching for that keyword across the USA. Time here is measured, for simplicity, as the number of days since January 1, 2020. For example, March 12 which is the day that Google searches peaked in the USA is day 71 .

Notice that there is an early bump in searches peaking in January 28. This corresponds to China's lockdown of Wuhan, which began January 23. Following a nearly month-long lull, searches rise rapidly in March. Searches continue through April but at a slowing pace.

The question of the paper, though, is whether differentiable resident interest, measured by Google searches, exists and correlates with policy. To provide some graphical, suggestive evidence, instead of providing the aggregate USA search behavior over time, I depict separately the search behavior of the first two states to issue the order (California and New York) and the last two states (Missouri and South Carolina) (Fig. 3). ${ }^{7}$

What stands out is the observation that California and New York see more internet searching in days 20 through 60 than Missouri and South Carolina. All peak around

\footnotetext{
7 New Jersey and Illinois also started their lockdowns the same day as New York, but they are omitted so for graphical clarity.
} 
Fig. 3 "Coronavirus": Early versus Late Orders. Daily number of searches, relative to the peak on March 12, 2020, for the search term "Coronavirus" in the USA between January 1, 2020 and April 23, 2020. California's Stay-at-Home order took effect March 19 and New York's began March 22 (days 78 and 81, respectively). Missouri and South Carolina's Stay-at-Home orders took effect April 6 and April 7, respectively (days 96 and 97)

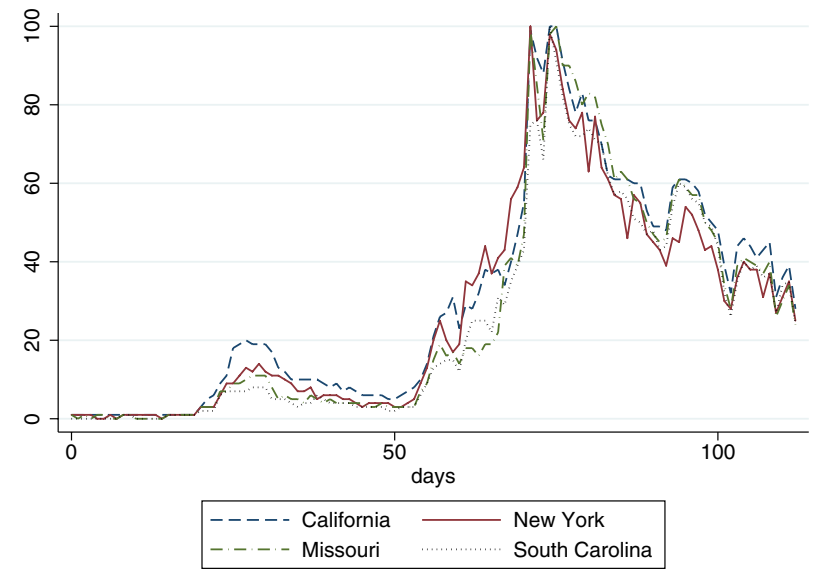

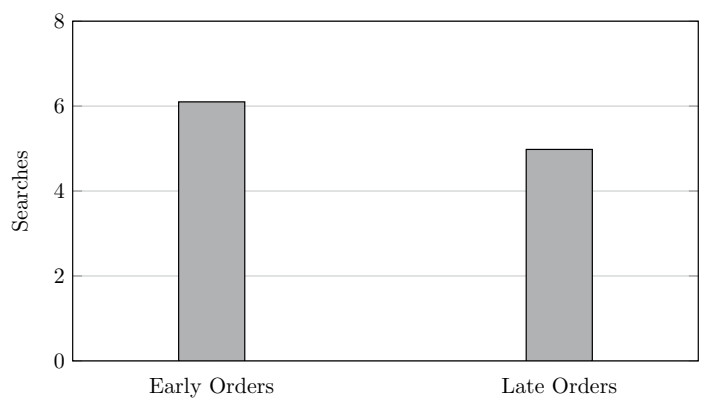

Fig. 4 Early Online Searching. Each column is a simple average of the averages. That is, the search value for each state between January 19 and February 20 is averaged. These values for the eight early adopting states (California, Illinois, Louisiana, New Jersey, New York, Ohio, Oregon) are averaged together to give the value for early orders. A similar calculation is done for the eight late adopting states (Alabama, Florida, Georgia, Maine, Mississippi, Missouri, South Carolina, Texas)

March 12 and taper off similarly afterwards. This suggests that it is differences in past searches that correlates with policy. To investigate this further, I focus on this early period of resident attention. Specifically, I consider the period from January 19 to February 20. The beginning date corresponds to the first reported case in the USA. As a crude, yet simple, comparison, for each state I average the value of Coronavirus ds $_{\text {s }}$ across this time period. I then average these values (unweighted) for the first eight states to implement their Stay-at-Home order, and then again for the last eight states. Figure 4 depicts the difference in these averages.

The late adopting states average $18 \%$ fewer daily searches, relative to their own state's peak, over this time frame than the early adopting states. This is further suggestive evidence of an important relationship between the early resident interest and gubernatorial policy. 
Table 2 Google Search and the implementation of Stay-at-Home Orders

\begin{tabular}{lllll}
\hline & $(1)$ & $(2)$ & $(3)$ & $(4)$ \\
\hline Cumulative Searches & $1.498^{* *}$ & $1.667^{* *}$ & $1.559^{* *}$ & $1.263^{* * *}$ \\
& $(0.692)$ & $(0.817)$ & $(0.707)$ & $(0.469)$ \\
Daily Searches: Prior 7-days & & $-0.013 *$ & & \\
& & $(0.006)$ & & \\
Cumulative Death Toll & & & $2.3 \times 10^{-5}$ & \\
& & & $\left(1.4 \times 10^{-5}\right)$ & \\
State Fixed Effects? & Yes & Yes & Yes & Yes \\
Day Fixed Effects? & Yes & Yes & Yes & Yes \\
$R^{2}$ & 0.764 & 0.772 & 0.772 & 0.876 \\
AIC & -2552 & -2241 & -2606 & -4892 \\
$N$ & 5763 & 4859 & 5763 & 4972 \\
\hline
\end{tabular}

Dependent variable is equal to one if the state has a stay-at-home order in effect on that day. Daily data from January 1, 2020 to April 23, 2020 used for the fifty US states and the District of Columbia (downloaded April 25). Standard errors, clustered at the state level, presented in parentheses (51 clusters).

\section{Primary Results}

To provide a more formal analysis, I turn to the panel data set. The indicator variable Lockdown $_{d s}$ is the dependent variable. To capture the amount of early

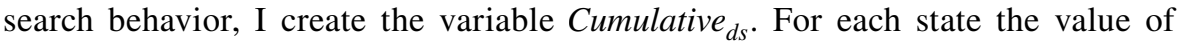
Coronavirus $_{d s}$ is summed for all 113 days of study. Further, for each day in each state, the sum of the values of Coronavirus $d s$ up to and including that day is derived. Cumulative $d s$ is this ratio and represents the proportion of all searching in the state that has occurred up to that time. Since the data set begins January 1, 2020, the day after the first known human infection, but before that fact was made public, Cumulative $_{d s}$ measures the full history of past searches. If governors are responding to voter attention in the virus, then those with higher values will be those who issue the orders earlier.

I will use state fixed effects and day fixed effects in the regressions. This is important because the state fixed effects capture all time invariant factors. One of importance is the total volume of searches. Coronavirus ${ }_{d s}$ is measured relative to that state's peak value $\overline{\text { Coronavirus }}_{s}$. Since this does not vary with $d$, it is absorbed into the fixed effect. As a result, I look at within-state variation in cumulative searches and how that corresponds to implementing Stay-at-Home orders. There are 51 state fixed effects. Time fixed effects control for countrywide issues, such as canceling NCAA men's basketball tournaments which made the virus very salient for basketball fans. Day fixed effects recognize that for early dates all states do not have an order in effect, while for later dates there is no more change in governor policy. There are 113 day fixed effects. Including day and state fixed effects allows for the coefficient on the Google search variable to capture its effect on the change in lockdown status. I use Coronavirus $_{d s}$ to create an additional, more-immediate explanatory variable. I will include the average number of searches in the seven days 
prior. Because this moving average uses lagged values, the number of observations reduces. Table 2 presents the results. Standard errors are clustered by state.

The first column provides the main result. Controlling for state characteristics and timing, there is a positive and statistically significant relationship between past internet searches and the likelihood that a governor issues a Stay-at-Home order.

In the second column, I include the most-recent search behavior. The coefficient on the cumulative searches grows in size. The coefficient on the number of searches is small and only weakly significant. In fact, it is negative. It is not necessarily reactionary decision making that explains the policy, but resident searches in the topic in the two months prior to the Stay-at-Home orders that matter. Only after resident attention has peaked do governors act.

The third column adds the daily cumulative death toll. The impact of the internet search behavior is mostly unchanged. Interestingly, the death toll is unrelated to the decision to issue the Stay-at-Home order. ${ }^{8}$ While the death toll is backward looking as it does not account for forecasts of expected deaths, the fact that it is unrelated to how quickly a state's Governor issues a Stay-at-Home order, while internet search behavior retains its strong association, strongly supports the "governor as a follower of public opinion" hypothesis.

In the fourth column, I exclude the seven states that never issue a Stay-at-Home order to check the results sensitivity. The finding in (4) mirrors that in (1). Hence, the result is not sensitive to the refusal of a few state governors to lock down their economy.

To engage in a calculation of the size of the effect, I conduct the following 'back of the envelope' derivation. On the day of the first issuance of a Stay-at-Home order, I calculate the standard deviation of the cumulative (relative) number of searches. If a state increased its cumulative searching by this standard deviation, then the probability it enters a lockdown in a day increases by $4.0 \%$.

\section{Heterogeneous Effects}

The previous result shows that the 'typical' governor is responding to resident interest in the virus. Not all governors, though, need respond the same way. In this section, I explore some heterogeneous effects.

First, policymaking can be a political calculation. With the 2020 election approaching, if a governor must immediately face voters in November, then one can be concerned that these governors are more likely to be responsive to voter's preferences. Evidence of election effects on fiscal policy decisions are well documented (Biglaiser and Mezzetti 1997). Therefore, I disaggregate the effect of past searches differentiating those up for re-election from those who are not.

Second, due to political bases with potentially different values in the tradeoff between public health and economic health, one can be concerned that policymaking here follows partisan lines. In recent studies Allcot et al. (2020) and Barrios

\footnotetext{
${ }^{8}$ While not presented here, this is also the case if the seven-day moving average death toll is either added or used as a replacement for the cumulative death toll.
} 
Table 3 Potential Heterogeneous Effects

(1)

$1.266^{* * * *}$

(0.468)

$1.244 * * *$

(0.472)

Cumulative Searches $\times$ Republican

Cumulative Searches $\times$ Democrat

Cumulative Searches

Cumulative Searches $\times$ Economic Freedom

Cumulative Searches $\times$ Approval Rating

State Fixed Effects?

Day Fixed Effects?

adj. $R^{2}$

AIC

$N$
(2)

(3)

(4)
$1.145^{* * *}$

(0.438)

$1.227 * * *$

(0.443)

$2.244 * * *$

(0.688)

$2.149 * * *$

$-0.116^{* *}$

(0.045)

$-0.808^{*}$

(0.473)

Yes

Yes

0.769

$-2652$

5650

Dependent variable is equal to one if the state has a Stay-at-Home order in effect on that day. Daily data from January 1, 2020 to April 23, 2020 used for the fifty US states and the District of Columbia (downloaded April 25). Columns 1 and 2 exclude the six states that did not issue a Stay-at-Home order. Columns (3) and (4) exclude the District of Columbia since its leadership is not a governor (and does not have gubernatorial approval ratings) and is not included in the Economic Freedom of North America index. Standard errors, clustered at the state level, presented in parentheses (45/50 clusters).

et al. (2020) find important differences between individuals who identify as being Republican and Democrats in social distancing behavior, measured by smartphone locations, and in surveys of attitudes towards social distancing. This is supported by survey work conducted in late March identifying a relationship between partisan affiliation and attitudes and behaviors regarding responses to the pandemic (Gadarian et al. 2020). I disaggregate the effect of searches by whether the governor is a Republican or a Democrat.

Third, some states have a tradition of respect for economic freedom. Low taxes, low spending, and less regulation are implemented there. These states could be viewed as more pro-economy. Heavily taxed and heavily regulated states may have less qualms about causing economic harm in an attempt to achieve better public health. To investigate this, since economic freedom is a continuous variable, I add an interaction term between a state's economic freedom score and its cumulative searches.

Finally, the Stay-at-Home order is costly to families but creates a public good in improved health and less stress on the health care sector. Therefore, it seems 
reasonable to presume that a governor with more 'political capital' may be more willing to spend this capital on a lockdown, as opposed to one who is fighting for support from his/her citizens. Consequently, again, I interact the governor's most recent approval rating with the cumulative searches and add it to the specification. Table 3 provides all four sets of results. Again, state and day fixed effects are included and standard errors are clustered at the state level. ${ }^{9}$

The relationship between resident internet search behavior and the Stay-at-Home order decision is unaffected by whether the governor is up for election in 2020 or his/her partisan affiliation. The estimates for both are virtually identical. Republican governors are no less responsive to the voters than Democrats. The fact that Republican lead states are slower to execute Stay-at-Home orders and are more likely to not lock down the economy at all is not necessarily an artifact of partisan ideology, but a function of their voters' preferences.

The other two heterogeneous effect have merit. States with more economic freedom see less of a link between voter concern in the virus and the decision to issue the order. Leaders of the economically free lead. ${ }^{10}$ Similarly, governors with high approval ratings are less likely to be responding to resident search behavior. This is, again, consistent with leaders respected by their citizens being leaders, rather than following the current sentiments of the population. The direction of the relationship is not knowable-is it that leaders earn higher approvals, or does higher approval ratings give the governor the room to be a leader and do unpopular things?

\section{Conclusion}

I ask whether governors are leaders or followers by evaluating the relationship between the timing of the Stay-at-Home orders and the amount of Google searching for "Coronavirus" by of their residents. I find that a governor is more likely to issue the order if the residents have had a greater concern over the virus in the past, as measured by their search behavior. This suggest that, for the most part, governors are followers as would be the case in Downsian competition where the preferences of the median voter are adopted by the politician.

This channel is unrelated to whether the governor is up for re-election or his/ her partisan affiliation. Evidence suggests though, that this following behavior is stronger in states with less economic freedom and when the governor has a lower approval rating. Governors of states that are more economically free lead, as do those who are popular.

The goal here is not to document all determinants used in the decision to lock down a state's economy with a Stay-at-Home order. Other obvious factors such as

\footnotetext{
${ }^{9}$ Note that since the four additional variables (partisanship, election cycle, economic freedom, and approval) are all time invariant. The use of state fixed effects implies that separate control variables cannot be added. Only their interaction with Cumulative $_{d s}$ is used.

${ }^{10}$ While not presented here, if the economic freedom scores from the Freedom of the 50 States index are used instead (Ruger et al. 2018), the same findings arise.
} 
the number of confirmed cases, number of deaths, health care capacity, and exposure to China are all likely drivers. My focus here is on the question of leadership and to what degree governors are responding to heightened concern over the Coronavirus amongst their residents.

My analysis can say nothing about the normative value of these decisions. Was the lockdown worth it? Was the manner in which the health crisis handled the best way to have navigated the situation? I do not know. My focus is on the much smaller issue of the positive analysis of information and policy.

An important limitation is that I rely heavily on the validity of Google searching under the keyword "Coronavirus" to be a sufficiently correlated measurement of voter attention. Potentially, future work can leverage other sources of salience such as television news viewership, social media posts, etc. Heightened search behavior is not necessarily an indication of support for the lockdowns. It indicates the attention paid to the virus and residents demand for information. My work provides a first step towards the future investigations on policymaking during this crisis. It is also worth pointing out that I do not differentiate between the severity of the limitations imposed by the Stay-at-Home orders, including additional restrictions implemented during the lockdown, such as adding requirements of face masks in public. Similarly, since the focus is on governors and their decision making process, I do not include county and city governments separately acting.

Causation is notoriously difficult to assess. By showing that the cumulative internet searches, rather than the immediate searches occurring just before the implementation, is what is correlated with the decision, then it is past concern that is what matters. While not presented, if the following week's number of searches is used as the dependent variable and the lockdown is treated as the explanatory variable, the relationship is statistically insignificant. It does not seem that the lockdown is causing the searches. Coupled with the observation that the cumulative death toll is unrelated to the issuance of the Stay-at-Home order, one can be more confident that it is the interest by the residents in the virus, early in the pandemic, that governors are responding to. It is not certain that the results can be interpreted as causal, but the evidence suggests that it may be.

The normative implications of my 'governors as followers' result are not clear. Governance disconnected from the desires of the people can be expected to be largely undesirable. Majoritarian policies, though, can tyrannize the minority. The primary contribution of my work is to highlight the link between resident concern and gubernatorial decision making by exploiting a novel event.

Acknowledgements I thank Josh Hall, Zach Rodriguez, and Mark Wilson for helpful comments and suggestions.

\section{References}

Allcot, Hunt, Levi Boxell, Jacob Conway, Matthew Gentzkow, Michael Thaler, and David Y. Yang. 2020. Polarization and Public Health: Partisan Distances in Social Distances During the Coronavirus Pandemic, NBER Working Paper No. w26946. 
Barrios, John M., and Yael Hochberg. 2020. Risk Perception Through the Lens of Politics in the Time of the COVID-19 Pandemic, NBER Working Paper No. 27008.

Besley, Timothy, and Stephen Coate. 1997. An Economic Model of Representative Democracy. Quarterly Journal of Economics 112 (1): 85-114.

Biglaiser, Gary, and Claudio Mezzetti. 1997. Politicians' Decision Making with Re-Election Concerns. Journal of Public Economics 66 (3): 425-447.

Black, Duncan. 1948. On the Rationale of Group Decision-Making. Journal of Political Economy 56: 23-34.

Brodeur, Abel, Andrew E. Clark, Sara Fleche, and Nattavudh Powdthavee. 2020. Assessing the Impact of the Coronavirus Lockdown on Unhappiness, Loneliness, and Boredom Using Google Trends, Working Paper.

Downs, Anthony. 1957. An Economic Theory of Democracy. New York: Harper.

Gadarian, Shana Kushner, Sara Wallace Goodman, and Thomas B. Pepinsky. 2020. Partisanship, Health Behavior, and Policy Attitudes in the Early Stages of the COVID-19 Pandemic, Working Paper.

Hall, Joshua, and Bryan C. McCannon. 2021. Stay-at-Home Orders Were Issued Earlier in Economically Unfree States. Southern Economic Journal 87 (4): 1138-1151.

Holshue, Michelle L., Chas DeBolt, Scott Lindquist, Kathy H. Lofy, John Wiesman, Hollianne Bruce, Christopher Spitters, Keith Ericson, Sara Wilkerson, Ahmet Tural, George Diaz, and Amanda Cohn. 2020. The First Case of the Novel Coronavirus. New England Journal of Medicine 382: 929-936.

Lowry, Robert C., James E. Alt, and Karen E. Ferree. 1998. Fiscal Policy Outcomes and Electoral Accountability in American States. American Political Science Review 92 (4): 759-774.

Osborne, Martin J., and Al. Slivinski. 1996. Model of Political Competition with Citizen-Candidates. Quarterly Journal of Economics 111 (1): 65-96.

Ruger, William P., and Jason Sorens. 2018. Freedom of the 50 States: An Index of Personal and Economic Freedom 5th Edition. Washington D.C.: Cato Institute.

Simon, Dennis M. 1989. Presidents, Governors, and Electoral Accountability. Journal of Politics 51 (2): 286-304.

Stansel, Dean, Jose Torra, and Fred McMahon. 2019. Economic Freedom of North America 2019. Vancouver: Fraser Institute.

Publisher's Note Springer Nature remains neutral with regard to jurisdictional claims in published maps and institutional affiliations. 